$\begin{array}{lccc}\text { POLISH JOURNAL } & \text { OF } & \text { SOIL } & \text { SCIENCE } \\ \text { VOL. LIV } / 1 & 2021 & \text { PL ISSN 0079-2985 }\end{array}$

DOI: $10.17951 / \mathrm{pjss} / 2021.54 .1 .103$

\author{
NAFISEH YAGHMAEIAN MAHABADI*, \\ SHAHRAM MAHMOUD SOLTANI**
}

\title{
APPLICABILITY OF FUZZY AND FUZZY ANALYTIC HIERARCHY PROCESS METHODS TO DETERMINE THE OPTIMUM SOIL DEPTH IN LAND SUITABILITY EVALUATION FOR IRRIGATED RICE
}

Abstract. The conventional Boolean logic models of land suitability assessment disregard the continuity concepts of the soil and landscape which might cause inaccurate evaluation and classification. To overcome this uncertainty and consequent constraints, the fuzzy set theories were introduced. Therefore, the current study was undertaken to estimate the optimum soil depth that is used in land suitability evaluation for irrigated rice through the fuzzy sets theory and analytic hierarchy process (fuzzy AHP) in Guilan Province, Iran. The square root and quantitative land suitability evaluation methods were employed to calculate traditional land suitability indices (for depths $0-25,0-50,0-75$, and $0-100 \mathrm{~cm}$ ). Also, fuzzy and fuzzy AHP methods were used to explore new land indices. The Sarma similarity indices were used to compare the results of traditional and fuzzy methods for different soil depths. The results showed that the compatibility percentage between the representative pedons $(0-100 \mathrm{~cm})$ and the findings of this research $(0-50$ and $0-75$ $\mathrm{cm}$ ) was remarkable. Furthermore, the highest compatibility percentage of land suitability class was related to the comparison of these two former depths and 0 to $100 \mathrm{~cm}$ depths in each of the two used fuzzy methods. Besides, except for $0-25 \mathrm{~cm}$ depths, actual yield revealed a significant and positive correlation with the rest three soil pedon depths. These findings show that consid-

* Department of Soil Science, Faculty of Agricultural Sciences, University of Guilan, Rasht, Iran.

** Soil and Water Dept., Rice Research Institute of Iran, Agricultural Research, Education and Extension Organization, Rasht, Iran. Corresponding author: shmsoltani@gmail.com 
ering 0 to $50 \mathrm{~cm}$ soil depth might be a relevant alternative as the optimal depth to evaluate land suitability for rice in paddy fields in Guilan rice-growing area.

Keywords: multi-criteria land evaluation, fuzzy set theory, rice, yield

\section{INTRODUCTION}

Nowadays, the most effective decisions making to find solutions for arable land suitability constraint is fundamental for higher land productivity and better environmental sustainability (Kurtener et al. 2004). This goal is usually achieved through proper land use planning (LUP), which requires a continuous monitoring of land use changes and proper and sustainable use of current land resources. Land suitability evaluation (LSE) programs are the precondition of all sustainable land use projects (Van Niekerk and Von Solms 2010). Land suitability assessment is defined as the land's classification in terms of its suitability for a defined use. Hence, the major object of the land evaluation programs is to determine the land suitability for the alternative, actual, or potential land uses that are relevant to the area under consideration without deterioration (De la Rosa and Van Diepen 2002). Land evaluation is carried out to predict land performance, both in terms of the expected benefits (despite of all constraints) to productive land use, as well as the expected environmental degradation due to these uses (Rossiter 1996). Land evaluation procedures focus increasingly on the use of quantitative procedures to enhance the qualitative interpretation of land resource surveys (Braimoh et al. 2004).

Land evaluation is a procedure of decision making that depends on biophysical factors but still requires knowledge of social and institutional factors to be able to evaluate the consequences of decisions (Bacic 2003). In the multi-criteria decision-making (MCDM) method, which is used to determine the optimum type of land utilization for a given area, the unequal importance of different land criteria is considered. The investigation of several alternatives taking into account multiple criteria and conflicting objectives is the main goal of multi-criteria evaluation (MCE) techniques. In these techniques, it is necessary to select alternatives and rank them according to their degree of attractiveness (Ceballos-Silva and Lopez-Blanco 2003).

In the traditional studies of land suitability evaluation, the land units fit among discrete classes and can only be assigned to one of the primary classes that are defined for land suitability. Therefore, the method is not able to show the continuous reality of land and soil spatial variability. Fuzzy set methodologies in land suitability evaluation have success in dealing with representations of vague, incomplete, and uncertain information. The fuzzy land evaluation has the potential for defining continuous suitability classes rather than using binary (suitable or not suitable) or other categorical discrete suitability assessments (Bagherzadeh and Gholizadeh 2016, Yaghmaeian Mahabadi et al. 2012). The 
application of the fuzzy set theory (Zhu et al. 2010), instead of categorizing observations into completely separate and discrete groups, group them into continuous classes (McBratney and Odeh 1997), assigning probabilities of belonging to a given class.

Elaalam (2010) differentiates Boolean and fuzzy analytic hierarchy process (AHP) methods to land suitability evaluation for barley, wheat, and maize crops in the north-western region of Jeffara Plain in Libya. Their results displayed that the fuzzy AHP approach introduced land suitability classes as continuous values, while using the Boolean approach results in crisp sets, which are less realistic in nature. Braimoh et al. (2004) used the fuzzy set and interpolation procedures for land suitability evaluation for maize in Northern Ghana. Their result showed that using the fuzzy procedure is useful for land suitability evaluation, mainly in usages where subtle variation in soil quality is of major interest. According to Prakash's (2003) results, the AHP method failed to address the uncertainty through the pairwise comparison analysis and this was the path for the integration of fuzzy set models in the AHP method. Servati et al. (2013) reported that the fuzzy approach provided better results than the parametric square root method for evaluating the suitability of alfalfa for lands in Khajeh region located in East Azerbaijan province, Iran. Qiu et al. (2014) concluded that fuzzy models achieve better predictive accuracy than their classic counterparts for land suitability/capability evaluation. The results showed that by incorporating fuzzy suitability membership of environmental factors in the modeling process, these fuzzy models also produce more informative fuzzy suitability maps. Mahdavi Firoozabadi et al. (2016) compared two fuzzy methods to determine the optimum soil depth in land suitability evaluation for wheat. The results showed that the highest compatibility percentage of land suitability class was related to a comparison of 0 to 60 and 0 to $100 \mathrm{~cm}$ depths in each of the two fuzzy methods. This fact shows that 0 to $60 \mathrm{~cm}$ depth could be a relevant alternative for the optimal depth to evaluate land suitability for wheat.

According to the literature review, land suitability assessment must have an interdisciplinary approach and thus should use a multi-criteria decision-making method, and on the other hand, modelling of soil system without fuzzification is not realistically describable. Therefore, it is necessary to use both of the multi-criteria decision making and fuzzy system for an accurate description of land potentiality at different land uses. Hence, further investigation on using the fuzzy set methodology in the context of a decision-making process, as the analytic hierarchy process (AHP) to land evaluation, is needed.

Soil depth is one of the most important physical properties of soils that directly influences the plant growth and development, and is also always considered in land suitability studies. A deep well-drained soil shows a root penetration until below $150 \mathrm{~cm}$ for most crops. For annual crops, the dense root system is usually at a depth of less than $60 \mathrm{~cm}$, while most tree crops even have a dense 
to moderate root system until the depth of $150 \mathrm{~cm}$. It has been considered that the optimal depth represents two times the depth at which we find a $60 \%$ of the root system. Experience has shown that most crops will produce excellent yields with an effective root zone depth of 90-100 cm. Consequently, for almost all crops, the depth of $100 \mathrm{~cm}$ of soil is included in the land suitability assessment calculations (Banai 1993).

The depth of which the land index has to be calculated must be defined for each land utilization type. The first approach considers that for a specific land utilization type all horizons have similar importance to the weighted average of the profile section until the considered depth for each characteristic. An alternative approach considers that the importance of a horizon becomes greater when its position is nearer to the surface, in this case a different proportional rating can be given to the depth sections of the profile in such a way that they increase when approaching the surface. Therefore, the profile can be subdivided into equal sections; to each of these sections, one attributes a weighting factor starting with a minimum value indepth and becoming gradually greater when approaching the surface section. The depth to be considered should coincide with the normal depth of the root system in deep soil (Sys et al. 1991).

Guilan Province, one of the most important rice-growing regions in the north of Iran, covering an area of 238,000 hectares, has an important contribution to national food security. It should be noted that the puddle zone for rice cultivation is $0-25 \mathrm{~cm}$. Moreover, in recent years, there has been increasing concern over land suitability evaluation in this region using FAO quantitative and qualitative methods, because, e.g. the Boolean-based methods (FAO method) ignore the continuous nature of the soil, landscape variation, and uncertainties in measurement. In reality, these assumptions may be invalid. Therefore, applying the multi-criteria decision-making strategy and abilities and capabilities of fuzzy systems can provide more reliable results in land suitability assessment, and determination of the optimum soil depth for land suitability studies. The current study was undertaken to estimate the optimum soil depth that is used in land suitability evaluation methods by using the fuzzy sets theory and analytic hierarchy process (fuzzy AHP) for irrigated rice in Guilan Province.

\section{MATERIALS AND METHODS}

\section{Study area}

Guilan Province (GP) is located between $36^{\circ} 33^{\prime}-38^{\circ} 27^{\prime} \mathrm{N}$ and $48^{\circ} 32^{\prime}-$ $50^{\circ} 36^{\prime} \mathrm{E}$, and covers an area of $14,044 \mathrm{~km}^{2}$ in the Caspian Sea coastal plain (Fig. 1). According to the last crop survey of the Jahad Agriculture Organization of Guilan Province, JAOGP (2017), 15\% of GP consists of irrigated rice paddy 
fields $(200,000 \mathrm{ha})$, the second rice production area of Iran. Elevations within the GP range from -7 to $>2,000 \mathrm{~m}$. The slope of almost all of paddy fields is less than $0.5 \%$.

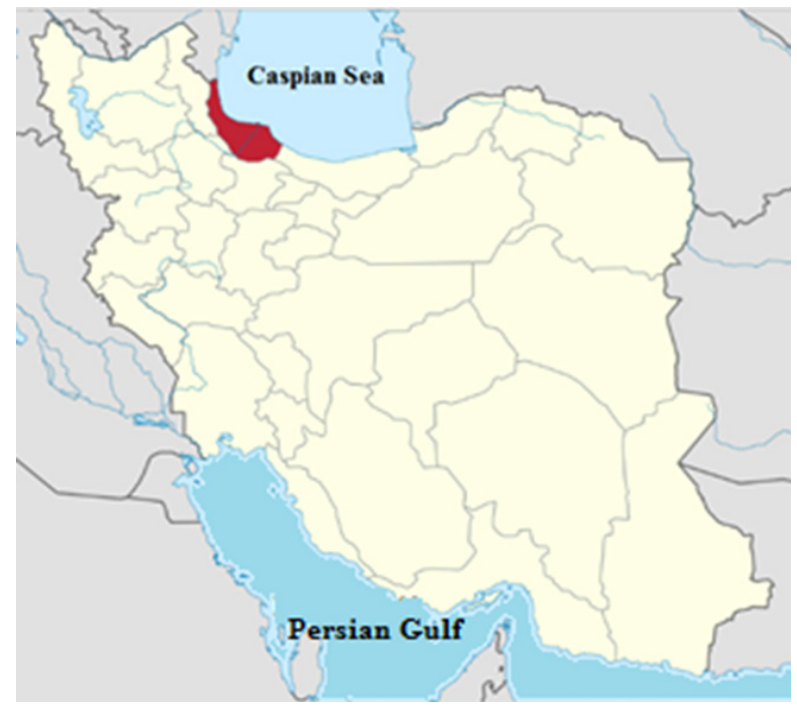

Fig. 1. The map of Guilan Province at country scale

The climate characteristics which are used in land suitability evaluation of rice (temperature, rainfall, relative humidity, etc.) were collected from the data bank of the Rasht synoptic meteorological station. The study area has a mean annual rainfall of $1,294 \mathrm{~mm}$ that is concentrated in autumn and winter seasons. The minimum and the maximum relative humidity of this area is $76.4 \%$ and $86.4 \%$, respectively. The mean annual temperature of GP is $15.8^{\circ} \mathrm{C}$. The warmest period of the year is from 11 June to 11 July with a mean of the maximum temperature of $28.8^{\circ} \mathrm{C}$, and the coldest period of the year is from October to early January, when the mean of the minimum temperature is as low as $4.2^{\circ} \mathrm{C}$. The annual potential evapotranspiration has a mean value of $720 \mathrm{~mm}$ (Akef 2005). According to the climatic data, the ombrothermic curve and the Amberje climate classification, the soil moisture and temperature regimes (SSS 2017) are Udic/Aquic and Thermic, respectively. In addition, the climate is very humid. Soil orders present are Alfisols, Inceptisols, and Entisols according to Soil Taxonomy (USDA, 2014) which is equal to Stagnisols, Cambisols and Fluvisols based on the world reference-based soil classification, respectively. The major crops in paddy fields are rice (Oryza sativa L.) as the first crop, and vegetables as second crops in the rice-based cropping system. 


\section{Data collection}

The basic data used for the current study included: (1) soil survey of Guilan coastal plain (GAOGP 2007); (2) annual rice yield survey of paddy fields in GP (JAOGP 2017), (3) rice growth requirements and (4) climatic data. When collecting soil pedon data, a primary step was to ensure a proper spatial distribution of soil profiles considered. With this criterion, 68 soil pedons and their related rice yield records were selected in the East and center of GP.

\section{Quantitative land suitability evaluation}

Qualitative and quantitative socio-economic land suitability evaluation was used according to Sys et al. $(1991,1993)$ in the study area for rice production. Soil and land characteristics (topography, soil depth, wetness and drainage, soil texture and structure, gravel, calcium carbonate, cation exchange capacity, organic matter, $\mathrm{pH}$, and EC) were matched with crop requirements, based on Sys et al. (1991) and other tables proposed by the Iranian Soil and Water Research Institute (Givi 1997). The limitation level of all the soil and climatic characteristics for rice cultivation was rated between 0 and 1 . The qualitative parametric method (square root) was used to calculate the land indices according to Sys et al. (1993).

All calculations were done in sequential soil depths: 0-25, 0-50, 0-75, and $0-100 \mathrm{~cm}$. Then, the rice predicted yield was calculated by multiplying the soil index of each observation point (at the relevant depth) by the potential (maximum) yield. We used the agro-ecological zoning (AEZ) model to calculate the potential yield (Kassam 1977). The equation is as follows:

$$
\mathrm{Y}=0.36 \text { bgm.KLAI.Hi } /\left((1 / \mathrm{L})+0.25 \mathrm{C}_{\mathrm{t}}\right)
$$

where, $Y$ - crop potential yield $\left(\mathrm{kg} \mathrm{ha}^{-1}\right)$; $b g m$ - maximum gross biomass production rate $\left(\mathrm{kg} \mathrm{CH}_{2} \mathrm{O} \mathrm{ha}^{-1} \mathrm{hr}^{-1}\right) ; K L A I$ - leaf area index at maximum growth rate; $\mathrm{Hi}$ - harvest index; $L$ - crop growth cycle (day); $C t$ - respiration coefficient

\section{Fuzzy approaches in land evaluation}

Applying the fuzzy logic to land suitability evaluation can be done using two approaches: fuzzy calculations (fuzzy numbers and intervals) and semanticimportmodel (SIM). In this research, both approaches have been used.

\section{1 - fuzzification of land index}

In this method, fuzzification of the calculated land index (usually between 0 and 100) is performed as trapezoidal fuzzy intervals (Fig. 2). Before running the 
fuzzy method, the land indices (Sys et al. 1991) obtained by the conventional land suitability method (square root) were converted into the fuzzy suitability classes.
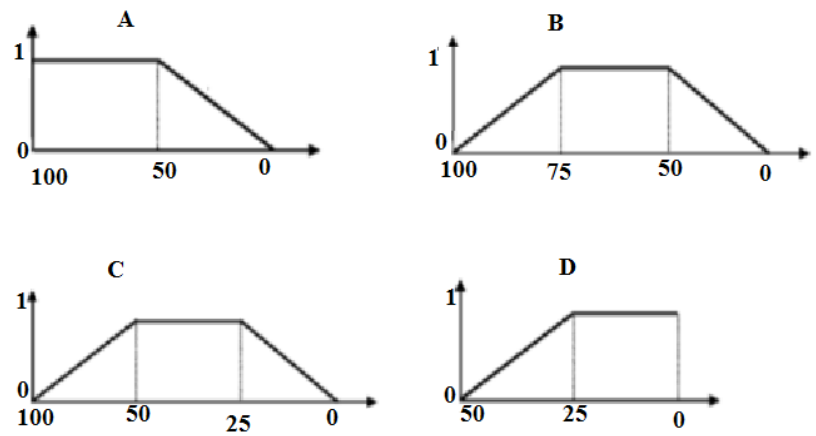

Fig. 2. Trapezoidal fuzzy intervals to fuzzification of land suitability classes [A - highly suitable

[S1], B - moderately suitable [S2], C - marginally suitable [S3] and D - N [not suitable]]

\section{2 - fuzzy analytic hierarchy process (fuzzy AHP)}

In this study, SIM was used to generate membership values for land characteristics. For the land characteristics that are considered in the study, Sigmoid and Kandel membership functions (Fig. 3) were established based on the rice growth requirements (Givi 1997, Sys et al. 1991) to express the degree to which the value of a land characteristic belongs to a certain land suitability classes (equations 2 and 3 ). Then the membership values of the different land characteristics (soil and climate) are subsequently arranged in a characteristic matrix (R).

$$
\operatorname{MF}(\mathrm{x})=\left\{\begin{array}{cr}
0 ; & x<\alpha \\
2(x-\alpha) /(\gamma-a)^{2} ; & \alpha \leq x<\beta \\
1-2\left((x-\gamma) /(\gamma-a)^{2}\right) ; & \beta \leq x<\gamma \\
1 ; & x \geq \gamma
\end{array}\right.
$$

where, $M F(x)$ is membership function; $x$ is the value of land characteristic; $\alpha, \beta$, and $\gamma$, at which membership function values are $0,0.5$, and 1 , respectively.

$$
\mathrm{MF}(\mathrm{x})=\left\{\begin{array}{cc}
\frac{1}{1+\left(\frac{x-b_{1}}{d_{1}}\right)^{2}} & \mathrm{x}<b_{1} \\
1 & b_{1} \leq x \leq b_{2} \\
\frac{1}{1+\left(\frac{x-b_{2}}{d_{2}}\right)^{2}} & \mathrm{x}>b_{2}
\end{array}\right\}
$$

where, $M F(x)$ is membership function; $b_{1}$ and $b_{2}$ are a lower crossover point and an upper crossover point, respectively; $d_{1}$ and $d_{2}$ have specified the width of the transition zone. 

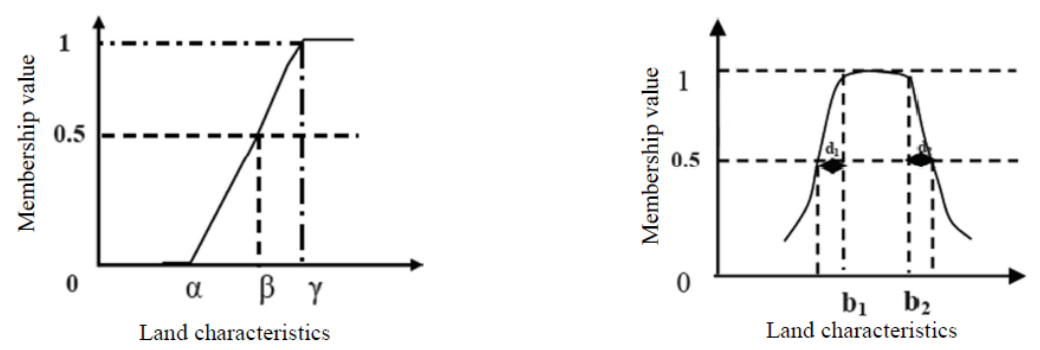

Fig. 3. Sigmoid and Kandel fuzzy membership functions

Land characteristics have a different impact on crop performance. Their relative importance concerning crop yield can be expressed by their weight value, which can be found in the weight matrix (W). The AHP method was used to calculate the weight of each land characteristic concerning rice grain yield. Figure 4 shows the hierarchical structure used in this study. To make the pairwise comparisons at each level of the hierarchy, decision-makers can develop relative weights, called "priorities", to differentiate the importance of each land characteristic. For this purpose, the qualitative scale proposed by Saaty (2014), from 1 to 9 was utilized (Table 1). Then, to aggregate the relative weights of various levels, matrices of relative weights were multiplied at each level of the hierarchy.

Finally, the consistency ratio (Malczewski 1996) of the pairwise matrix was calculated, which indicates the probability of random assignment of the ratings. A consistency ratio of 0.1 or less is considered acceptable (Saaty 2014). The pairwise comparison matrix can be produced by the Idrisi software.

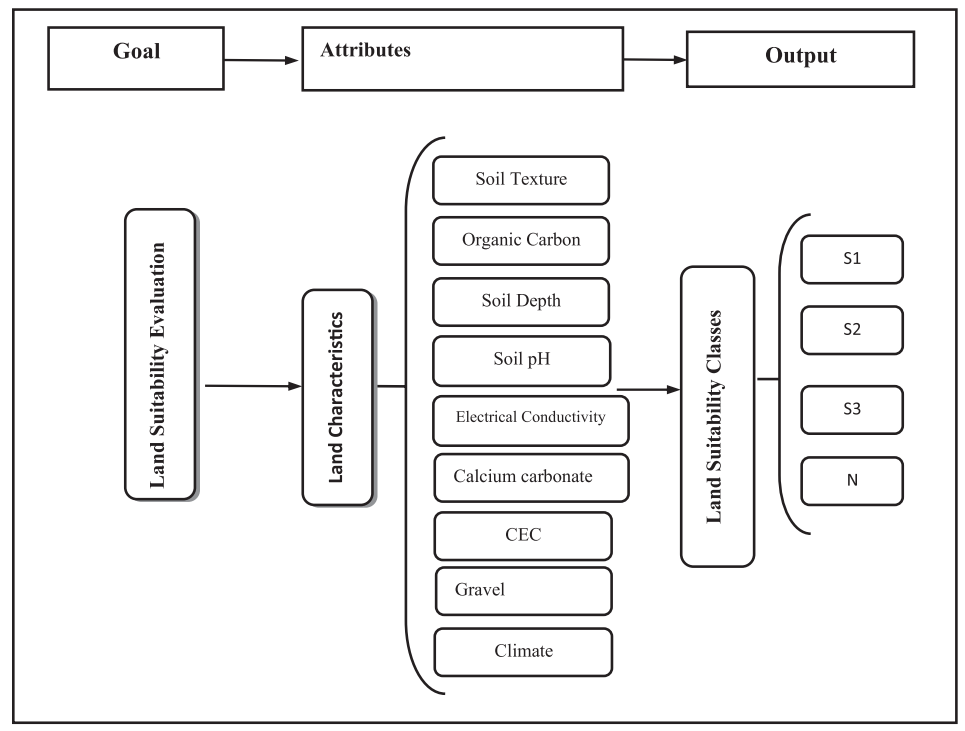

Fig. 4. Hierarchical organization of the land criteria for rice production 
The evaluation matrix (E) for each observation point is obtained by multiplying the weight and characteristic matrix through the fuzzy set operator according to the following equation (Van Ranst et al. 1996):

$$
\mathrm{E}=\mathrm{W}^{\circ} \mathrm{R}
$$

where, ${ }^{\circ}$ is the fuzzy set operator. It can be created as a Triangular Norm instead of the minimum and a Triangular Conorm instead of the maximum (Ruan 1990).

Table 1. Saaty's (2014) nine-point scale for relative importance

\begin{tabular}{cc}
\hline Intensity of importance & Definition \\
\hline 1 & Equal importance \\
\hline 2 & Equal to moderate importance \\
\hline 3 & Moderate importance \\
\hline 4 & Moderate to strong importance \\
\hline 5 & Strong importance \\
\hline 6 & Strong to very strong importance \\
\hline 7 & Very strong importance \\
\hline 8 & Very strong importance to extremely strong importance \\
\hline 9 & Extreme importance \\
\hline
\end{tabular}

$\mathrm{i}=1,2, \ldots, \mathrm{n} ; e_{j}=\min \left(a_{1}+a_{2}+a_{n}, 1\right)$ with $a_{1}=\max \left(0, w_{i}+r_{i j}-1\right)$

where, $w_{i}$ is the weight value for the $i^{\text {th }}$ characteristic, and $r_{i j}$ denotes an element of the matrix R for the $i^{\text {th }}$ characteristic under $j^{\text {th }}$ suitability class and $e_{j}$ is the element of matrix $E$ that expresses the degree of membership value to suitability classes $\mathrm{S} 1$ to $\mathrm{N} 2$.

To calculate the land index, the sum of elements of matrix $E$ is equal to 1 (standardization) and the new elements of this matrix are multiplied by the mean of the indices of the different land suitability classes according to the following equation (Van Ranst et al. 1996).

$$
L I=\sum\left[d\left(E_{j}\right) * A_{j}\right]
$$

where, $L I$ - land index; $d$ - the normalized (standardized) value of land evaluation matrix (E); $A_{j}$ - mean of maximum and minimum land indices of the $j^{\text {th }}$ land suitability class.

Finally, the results of two applied fuzzy approaches were compared for different soil depths by using the similarity index equation developed by Sarma (2006) as follows:

$$
S=\frac{\mathrm{A} \cap \mathrm{B}}{\mathrm{A} \cup \mathrm{B}}=\frac{\min (\mathrm{A}, \mathrm{B})}{\operatorname{Max}(\mathrm{A}, \mathrm{B})}
$$


where, $S$ is similarity value, $A$ and $B$ denote the membership value of land suitability classes and $\cap$ and $U$ represent the standard intersection and union fuzzy set operations, respectively.

\section{RESULTS AND DISCUSSION}

\section{Descriptive statistics of soil properties and rice grain yield}

Table 2 summarizes the statistical results of soil properties, as well as the actual and predicted rice grain yield in the study area. The mean of the clay content at the surface and subsurface layers were $36.4 \%$ at 0 to $25 \mathrm{~cm}$ and $40 \%$ at 25 to $50 \mathrm{~cm}$ of soil depths, which is irregularly distributed with depth. The relatively high clay content is due to the nature of the parent material, and it normally increases with depth due to clay illuviation by rainfall and/or irrigation, while sand contents remain rather constant. Increasing clay contributes to establishing a non-penetrating layer under the plow layer that prevents vertical water infiltration and creates flooded conditions for rice growth in paddy fields. Puddling practice produces then a compact layer on these heavy texture, rice paddy soils (Cheng et al. 2009, Owliaie and Ghiri 2013).

Table 2. Summary statistics of soil characteristics and estimated yield (68 soil profiles)

\begin{tabular}{cccccccc}
\hline Criterion & Depth $(\mathrm{cm})$ & $\mathrm{CV}(\%)$ & $\max$ & $\min$ & $\begin{array}{c}\text { Standard } \\
\text { deviation }\end{array}$ & median & mean \\
\hline Clay (\%) & $0-25$ & 33.5 & 57.6 & 1.2 & 12.2 & 39.4 & 36.4 \\
& $25-50$ & 37.5 & 60.8 & 1.1 & 15.0 & 44.8 & 40.0 \\
& $50-75$ & 36.4 & 64.0 & 0.0 & 14.5 & 43.0 & 39.8 \\
& $75-100$ & 40.5 & 80.0 & 0.0 & 16.1 & 42.9 & 39.7 \\
\hline Sand (\%) & $0-25$ & 45.0 & 89.7 & 1.2 & 11.3 & 20.7 & 25.1 \\
& $25-50$ & 46.9 & 96.9 & 0.3 & 12.3 & 20.0 & 26.2 \\
& $50-75$ & 44.0 & 96.9 & 0.5 & 12.2 & 21.4 & 27.7 \\
& $75-100$ & 50.2 & 97.0 & 0.5 & 14.1 & 21.2 & 28.1 \\
\hline Organic carbon $(\%)^{0}$ & $0-25$ & 93.7 & 6.5 & 1.23 & 3.0 & 2.1 & 3.2 \\
& $25-50$ & 93.3 & 2.8 & 0.91 & 1.4 & 1.0 & 1.5 \\
& $50-75$ & 90.9 & 1.7 & 0.32 & 1.0 & 0.7 & 1.1 \\
& $75-100$ & 90.6 & 0.7 & 0.0 & 0.58 & 0.59 & 0.64 \\
\hline CaCO $_{3}$ equivalent $(\%)^{0-25}$ & 26.2 & 19.7 & 0.0 & 1.1 & 2.0 & 4.2 \\
& $25-50$ & 27.2 & 21.5 & 0.0 & 1.2 & 1.7 & 4.4 \\
& $50-75$ & 32.5 & 20.0 & 0.0 & 1.4 & 1.5 & 4.3 \\
& $75-100$ & 34.7 & 20.0 & 0.0 & 1.6 & 1.6 & 4.6 \\
\hline $\mathrm{EC}_{\mathrm{p}}\left(\mathrm{dS} \mathrm{m}{ }^{-1}\right.$ at $\left.25^{\circ} \mathrm{C}\right)$ & $0-25$ & 71.8 & 1.4 & 0.16 & 0.79 & 0.87 & 1.1 \\
& $25-50$ & 69.8 & 1.1 & 0.20 & 0.51 & 0.7 & 0.73 \\
& $50-75$ & 77.0 & 0.94 & 0.10 & 0.47 & 0.7 & 0.61 \\
& $75-100$ & 80.9 & 0.75 & 0.10 & 0.34 & 0.7 & 0.42 \\
\hline
\end{tabular}




\begin{tabular}{cccccccc}
\hline Criterion & Depth $(\mathrm{cm})$ & $\mathrm{CV}(\%)$ & $\max$ & $\min$ & $\begin{array}{c}\text { Standard } \\
\text { deviation }\end{array}$ & median & mean \\
\hline $\mathrm{pH}$ (water, 1:2.5) & $0-25$ & 9.0 & 7.6 & 6.7 & 0.67 & 7.4 & 7.4 \\
& $25-50$ & 8.7 & 7.9 & 6.5 & 0.63 & 7.5 & 7.2 \\
& $50-75$ & 8.7 & 7.9 & 6.5 & 0.62 & 7.6 & 7.1 \\
& $75-100$ & 8.2 & 7.7 & 6.4 & 0.58 & 7.5 & 7.0 \\
\hline (CEC) cmolc kg-1 $^{-1}$ & $0-25$ & 75.0 & 68.4 & 12.3 & 19.8 & 16.4 & 26.4 \\
& $25-50$ & 77.6 & 44.5 & 10.5 & 14.9 & 19.8 & 19.2 \\
& $50-75$ & 87.1 & 45.0 & 9.4 & 12.9 & 13.0 & 14.8 \\
& $75-100$ & 84.0 & 45.0 & 8.3 & 11.6 & 7.8 & 13.8 \\
\hline Estimated yield (t ha $\left.{ }^{-1}\right)$ & $0-25$ & 31.3 & 4.63 & 1.72 & 1.01 & 3.33 & 3.33 \\
& $25-50$ & 33.8 & 4.56 & 1.18 & 1.10 & 3.33 & 3.25 \\
& $50-75$ & 33.3 & 4.99 & 1.25 & 1.02 & 3.13 & 3.16 \\
& $75-100$ & 33.1 & 4.56 & 1.18 & 1.03 & 3.01 & 3.11 \\
\hline Actual yield (t ha-1) & - & 19.7 & 4.5 & 2.5 & 0.7 & 3.7 & 3.6 \\
\hline
\end{tabular}

The mean of organic carbon content at studied soil depths varied from $0.64 \%$ (min) and 3.2\% (max) (Table 2). Higher OC contents were observed in surface layers and showed a decreasing trend with depth. This supported the findings of Liu et al. (2014) who discovered that the long-term waterlogged conditions limit inhibiting C from microbial decomposition. Owliaie and Ghiri (2013) indicated that continuous rice cultivation significantly increased the OC (around $0.4 \%$ ), whereas soils of the east of Asia paddy fields have a higher OC (around 2-4.1\%) due to intensive rice cultivation (Pan et al. 2008). Lal et al. (2004) revealed that rice cultivation under submerged conditions can significantly increase total organic carbon content by the negative impact on decomposition and mineralization of soil organic matter, thus an accumulation of soil organic carbon can be expected (Lal 2004, Pan et al. 2008, Kögel-Knabner et al. 2010).

The depth distribution of calcium carbonate equivalent percentage was similar (Table 2) and less than 5\% in studied soils. Most of the gleyed paddy soils were neutral to slightly alkaline, with $\mathrm{pH}$ values that varied from 6.4 to 7.9 (with an average $\mathrm{pH}$ of 7.2). Also, the depth distribution pattern of soil $\mathrm{pH}$ was regular and the $\mathrm{pH}$ average (mean) decreased with increasing soil depth. Under anoxic soil conditions (paddy soils), the $\mathrm{pH}$ tends to rise to the neutral value (Mahmoud Soltani et al. 2015, 2016). Initially, the soil $\mathrm{pH}$ declines to the minimum value a few days after flooding due to a temporary increase in $\mathrm{CO}_{2}$ pressure of aerobic microorganism respiration activities and then rises to the nearly stable neutral value $(\mathrm{pH}=6-7)$ due to the beginning of reduction conditions in acid soils. In sodic soils, the soil $\mathrm{pH}$ decreases due to flooding conditions. This $\mathrm{pH}$ decline is more sensitive to changes in $\mathrm{CO}_{2}$ partial pressure than acid soils (Cheng et al. 2009). Furthermore, Akef (2005) has also reported that the reaction of paddy soils (especially in topsoils) irrigated by the Sepidrood river irrigation networks is higher than out of the network soils. The results of monitoring stations indicated that basic cations content of the above-mentioned river is relatively high (data are not shown). 
The maximum and minimum electrical conductivity values $\left(\mathrm{EC}_{\mathrm{p}}\right)$ $\left(\mathrm{dSm}^{-1} 25^{\circ} \mathrm{C}\right)$ were 0.1 and 1.4 , respectively. The mean of EC is regularly distributed and decreased with depth. The results of almost all soils indicated that the EC value was higher at the plow layer due to the higher evaporation of irrigation water.

The mean value of cation exchange capacity (CEC) varied from 13.8 to $26.4 \mathrm{cmol}_{\mathrm{c}} \mathrm{kg}^{-1}$ on the surface and in the subsoil, respectively. Similar to OC, the mean of CEC are regularly distributed and decreased with depth. This trend may be attributed to the effect of OC on CEC (Jaiyeoba 2003). Considering the reduction of soil organic matter, increasing clay content and decreasing cation exchange capacity with increasing depth, it can be stated that changes in the cation exchange capacity of the soils are more affected by the amount of organic matter. Furthermore, Gajri et al. (2002) indicated that the OC is more effective than clay content and clay mineral types on CEC variation in the paddy fields.

The variability of the selected soil properties is expressed in Table 2 by several parameters. Wang et al. (2009), Zhang et al. (2007), and Jian-Bing et al. (2006) stated that among these factors, CV is the most discriminating one. According to Zhang et al. (2007), the parameters were classified into most (CV $>90 \%)$, moderate (CV 10-90\%) and least $(\mathrm{CV}<10 \%)$ variable classes. The results indicated that the organic carbon was the most variable and the rest of properties in four depths were moderately variable. Notably, $\mathrm{pH}$ showed the lowest CV value (8.2-9.05\%) similarly to soils from other regions (Fu et al. 2010, Liu et al. 2014). In general, $\mathrm{pH}$ is considered to be a stable soil parameter (Bouma and Finke 1993).

Generally, topographic factors, land use, and erosion have affected the variations of soil characters (Jian-Bing et al. 2006). In paddy fields, variations of OC $\%$ are strongly related to management factors, especially puddling practice and its anoxic conditions, since it decreases organic matter decomposition. Furthermore, proper climatic conditions (high rainfall and optimum temperature) are important factors for increasing crop biomass and the subsequent high soil organic matter content (Davatgar et al. 2012). Nevertheless, Ayoubi et al. (2009) believed that long-term single cropping and uniform land management reduced soil variability through soil homogeneity processes.

The statistical data of actual and estimated rice grain yield in the study area is shown in Table 3. There were no significant differences between estimated yields (mean) of studied soil depths, but the estimated yield showed considerable differences with actual yield. Both estimated and actual yields have a moderate variability in the studied area. It might be considered that farm productivity is tuned by an interaction of numerous factors such as climatic conditions, soil characteristics (soil indices are less than 1), and crop genetic abilities. It is also possible that non-uniform irrigation patterns, cropping systems and agricultural management (i.e., fertilization, tillage regime) have affected the variability of crop production (Davatgar et al. 2012). On the other hand, considerable dif- 
ferences were found between potential yield $\left(5.3\right.$ t.ha $^{-1}$, calculated by equation 1 for the studied area) and actual yield (3.6 t.ha-1) due to soil index less than 1 and management level in the study area.

Comparison of different methods of land suitability evaluation for the studied soil depths

Table 3 summarizes the comparison between the obtained land suitability classes using the method of Sys et al. (1991) for all soil profiles down to the depth of $100 \mathrm{~cm}$ with the depths of less than $100 \mathrm{~cm}$. The results showed that the compatibility percentage between the 0 to $100 \mathrm{~cm}$ soil depth and these research findings at $0-50$ and $0-75 \mathrm{~cm}$ was remarkable, about 94.0 and $83.8 \%$, respectively.

Table 3. Comparison of qualitative land suitability classes of the soil profiles down to the depth of $100 \mathrm{~cm}$ compared with those down to less than $100 \mathrm{~cm}$

\begin{tabular}{ccc}
\hline $\begin{array}{c}\text { Depth } \\
(\mathrm{cm})\end{array}$ & $\begin{array}{c}\text { Compatibility percentage of observation } \\
\text { points with the land suitability class of } \\
\text { soil profiles down to the depth of } 100 \mathrm{~cm}\end{array}$ & $\begin{array}{c}\text { Number of observation points have the } \\
\text { same land suitability class as the soil pro- } \\
\text { file down to the depth of } 100 \mathrm{~cm}\end{array}$ \\
\hline $0-25$ & 47.0 & 32 \\
\hline $0-50$ & 83.8 & 57 \\
\hline $0-75$ & 94.0 & 63 \\
\hline
\end{tabular}

Tables 4 and 5 described the pairwise comparison matrices, normalized pairwise comparisons, and criteria weights for rice using the fuzzy AHP method. The final class of land suitability for each observation point is obtained by multiplying the matrices of weights and characteristics through the theory of fuzzy sets according to the fuzzy operator (Van Ranst et al. 1996).

Table 4. The normalized pairwise comparison matrices and criteria weights

\begin{tabular}{cccccccccccc}
\hline Criterion & $\begin{array}{c}\text { Ground- } \\
\text { water } \\
\text { depth }\end{array}$ & $\begin{array}{c}\text { Soil } \\
\text { texture }\end{array}$ & $\begin{array}{c}\text { Equivalent } \\
\mathrm{CaCO}_{3}\end{array}$ & $\begin{array}{c}\text { Soil } \\
\text { depth }\end{array}$ & OC & $\mathrm{pH}$ & $\mathrm{Ec}$ & $\mathrm{CEC}$ & Climate & Weight \\
\hline $\begin{array}{c}\text { Groundwater } \\
\text { depth }\end{array}$ & 0.05 & 0.05 & 0.10 & 0.16 & 0.03 & 0.03 & 0.08 & 0.02 & 0.08 & 0.058 \\
\hline Soil texture & 0.10 & 0.10 & 0.17 & 0.05 & 0.16 & 0.12 & 0.10 & 0.16 & 0.13 & 0.123 \\
\hline $\begin{array}{c}\text { Equivalent } \\
\mathrm{CaCO}_{3}\end{array}$ & 0.02 & 0.02 & 0.03 & 0.03 & 0.03 & 0.02 & 0.08 & 0.03 & 0.08 & 0.036 \\
\hline Soil depth & 0.10 & 0.31 & 0.20 & 0.16 & 0.32 & 0.18 & 0.10 & 0.16 & 0.17 & 0.190 \\
\hline $\mathrm{OC}$ & 0.15 & 0.05 & 0.10 & 0.04 & 0.08 & 0.16 & 0.10 & 0.16 & 0.13 & 0.098 \\
\hline $\mathrm{pH}$ & 0.10 & 0.05 & 0.14 & 0.05 & 0.08 & 0.06 & 0.06 & 0.03 & 0.08 & 0.073 \\
\hline Ec & 0.20 & 0.32 & 0.14 & 0.47 & 0.24 & 0.31 & 0.31 & 0.33 & 0.017 & 0.276 \\
\hline $\mathrm{CEC}$ & 0.25 & 0.05 & 0.10 & 0.08 & 0.04 & 0.19 & 0.08 & 0.08 & 0.13 & 0.111 \\
\hline Climate & 0.03 & 0.03 & 0.02 & 0.04 & 0.03 & 0.03 & 0.08 & 0.03 & 0.04 & 0.036 \\
\hline & & & & & & & & & & \\
\hline
\end{tabular}


Table 5. The pairwise comparison matrices of criteria

\begin{tabular}{|c|c|c|c|c|c|c|c|c|}
\hline Criterion & $\begin{array}{c}\text { Ground- } \\
\text { water } \\
\text { depth }\end{array}$ & $\begin{array}{c}\text { Soil } \\
\text { texture }\end{array}$ & $\begin{array}{c}\text { Equivalent } \\
\mathrm{CaCO}_{3}\end{array}$ & Soil depth & $\mathrm{OC}$ & $\mathrm{pH}$ & Ec & CEC Climate \\
\hline Groundwater depth & 1 & & & & & & & \\
\hline Soil texture & 2 & 1 & & & & & & \\
\hline Equivalent $\mathrm{CaCO}_{3}$ & 0.33 & 0.2 & 1 & & & & & \\
\hline Soil depth & 2 & 3 & 6 & 1 & & & & \\
\hline $\mathrm{OC}$ & 3 & 0.5 & 3 & 0.25 & 1 & & & \\
\hline $\mathrm{pH}$ & 2 & 0.5 & 4 & 0.33 & 0.25 & 1 & & \\
\hline $\mathrm{Ec}$ & 4 & 3 & 4 & 3 & 0.33 & 1 & 1 & \\
\hline CEC & 5 & 0.5 & 3 & 0.5 & 3 & 3 & 0.25 & 1 \\
\hline Climate & 0.5 & 0.33 & 0.5 & 0.25 & 0.5 & 0.5 & 0.25 & 0.33 \\
\hline
\end{tabular}

The results of the two applied fuzzy methods (fuzzy and fuzzy AHP) were compared for different soil depths (Table 7) and, also for the same depths (Table 8) by using the similarity index equation developed by Sarma (2006). The results of the present study for different soil depths (Table 7) demonstrated that the proposed methods have the highest similarity index for $0-75 \mathrm{~cm}$ and $0-100 \mathrm{~cm}$ depths. The highest calculated similarity indices through fuzzy and fuzzy AHP methods was about $50 \%$ for the same depths (Table 8). For this similarity, the proposed methods presented a clear unsimilarity (more than 50\%) too. It might be related to the fact that using the different weights and membership functions can lead to different results in the fuzzy AHP method. In other words, the effective land and climatic characteristics of rice production have various membership functions and weights. Thus, the land index is derived from the interaction between the fuzzy membership values and the weights associated with the evaluation criteria. The fuzzy AHP method can produce reasonable results because it addresses the uncertainties that are associated with boundary conditions in criteria, taking into account the effects of properties which happen to have values close to class boundaries. Moreover, the effective land and climatic characteristics of rice crop production are well organized in a hierarchical structure and consequently can facilitate the interaction of expert opinions and decision-making framework (Yaghmaeian Mahabadi and Rahimi Mashkle 2016).

Table 6. The similarity indices of fuzzy and fuzzy AHP methods for different soil depths

\begin{tabular}{ccc}
\hline Method & Depths $(\mathrm{cm})$ & Similarity percentage \\
\hline Fuzzy & $0-25,0-50$ & 67.7 \\
\hline $0-25,0-75$ & 43.2 \\
\hline $0-25,0-100$ & 38.4 \\
\hline $0-50,0-75$ & 88.6 \\
\hline $0-50,0-100$ & 85.4 \\
\hline $0-75,0-100$ & 91.7 \\
\hline
\end{tabular}




\begin{tabular}{ccc}
\hline Method & Depths $(\mathrm{cm})$ & Similarity percentage \\
\hline Fuzzy AHP & $0-25,0-50$ & 65.4 \\
\hline $0-25,0-75$ & 53.6 \\
\hline $0-25,0-100$ & 40.8 \\
\hline $0-50,0-75$ & 79.9 \\
\hline $0-50,0-100$ & 86.3 \\
\hline $0-75,0-100$ & 93.5 \\
\hline
\end{tabular}

Table 7. The similarity indices of fuzzy and fuzzyAHP methods for the same soil depths

\begin{tabular}{cc}
\hline $\begin{array}{c}\text { Depth } \\
(\mathrm{cm})\end{array}$ & Similarity percentage \\
\hline $0-25$ & 52.4 \\
\hline $0-50$ & 46.5 \\
\hline $0-75$ & 46.8 \\
\hline $0-100$ & 40.9 \\
\hline
\end{tabular}

The correlation coefficients between estimated and actual yields and calculated land indices by three methods (parametric, fuzzy, and fuzzy AHP) at four soil depths are shown in Table 8 . They show a low correlation between estimated and actual yield in the studied area. The low correlation coefficients reflected a major gap between actual and estimated yield. They are due to (1) the inadequacy of the crop growth requirements table for rice developed by Sys et al. (1991) (needs to be improved and modified as for the country condition), (2) the lack of consideration of farm management on crop growth requirements table (needs to be considered and modified) and (2) the use of agricultural crop physiological data instead of physiological characters of the specific variety of specific area (should be considered).

The predicted and actual yields for all studied depths has a positive and significant correlation with all calculated land indices. Similarly, actual yield showed a positive and significant correlation with all land indices, except for 0-25 cm (Table 8). On the other hand, except for 0-25 cm depths, actual yield revealed a significant and positive correlation with the land indices at the other soil depths. These findings show that 0 to $50 \mathrm{~cm}$ soil depth information might be already a relevant alternative for the optimal depth to evaluate land suitability for rice in paddy fields in Guilan rice-growing area, due to time-consuming and higher cost of $0-100 \mathrm{~cm}$ studies and the higher root content of $0-50 \mathrm{~cm}$.

Sys et al. (1991) stated that the optimal soil depth is calculated by redoubling of the soil depth that contains $60 \%$ of plant roots. The result of the current study is in line with Mahdavi Firoozabadi et al.'s (2016) finding that indicated 0-60 cm soil depth is the proper alternative of optimum soil depth for land suitability evaluation in Shahedih-Yazad for wheat. 


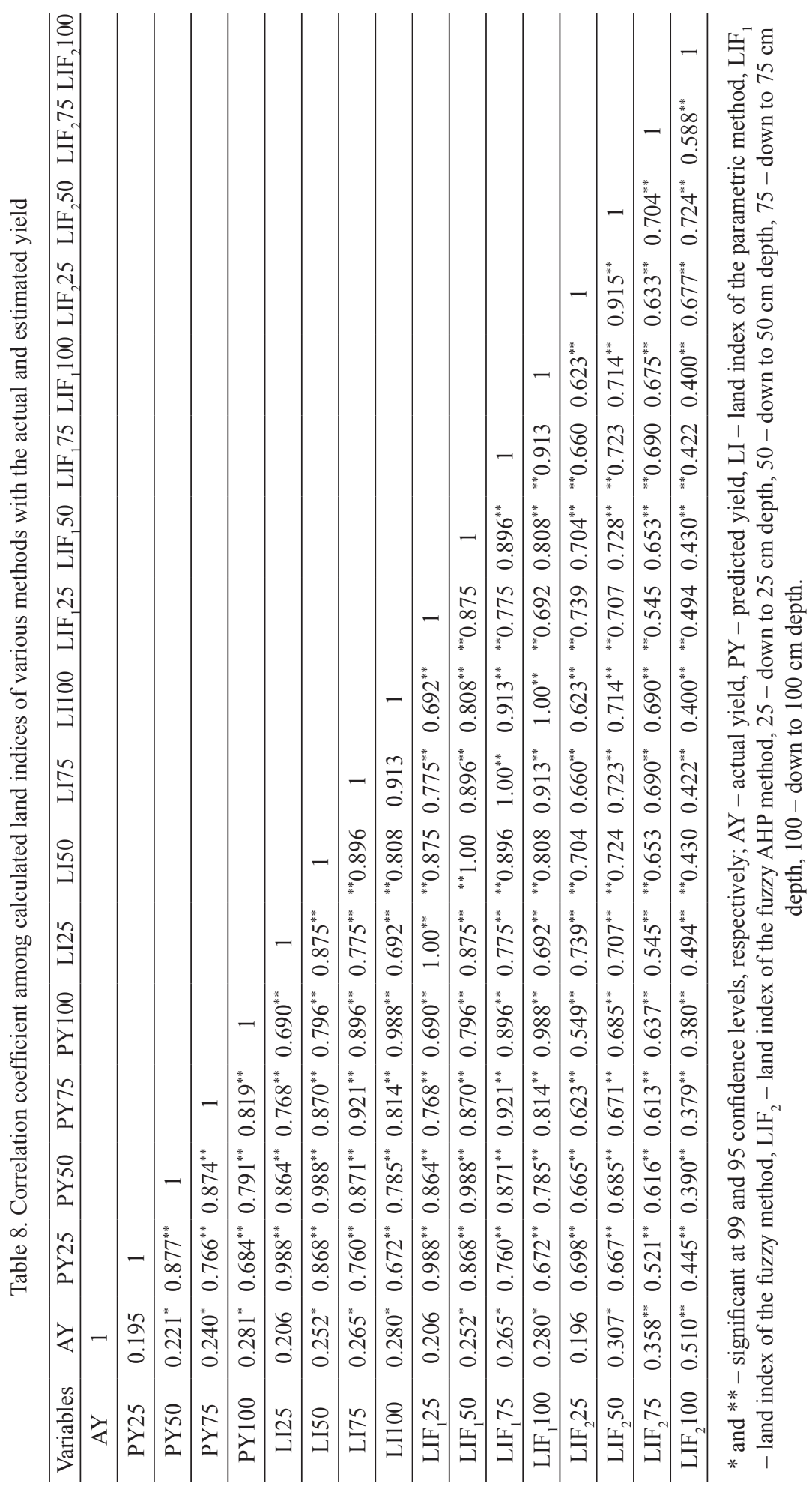


We assessed the accuracy of land suitability evaluation methods, based on the correlation between the land indices obtained by each of the parametric, AHP and fuzzy AHP methods for a depth of $100 \mathrm{~cm}$ with the observed rice yield (Table 8). The results obtained by the fuzzy AHP method are the most accurate $\left(\mathrm{R}^{2}=0.510\right)$, predicting the observed yield as compared with those obtained using other methods. Van Ranst et al. (1996), Tang et al. (1997), Moreno (2007), and Keshavarzi et al. (2010) have proven that the fuzzy sets methods compared to Boolean logic have more ability for land suitability evaluation. Comparing the three models (Boolean, fuzzy and fuzzy AHP), we find that each suitability class derived from the Boolean approach is associated with low and high values for joint membership functions when derived from fuzzy AHP and Ideal Point approaches, respectively. It can be concluded that the two used fuzzy methods are able to process the uncertainties associated with describing the land characteristics (Elaalem 2010). In line with the above-mentioned findings, Yaghmaeian Mahabadi et al. (2012) have evaluated qualitative land suitability for irrigated alfalfa and barley using four different methods (maximum limitation, parametric, AHP and fuzzy AHP). The results indicated that the highest correlation coefficient between the proposed methods and the observed yields were also obtained for fuzzy AHP. Also, this method estimated higher suitability classes (higher levels of membership values) for the irrigated alfalfa compared to irrigated barley.

To compare estimated land indices using traditional (parametric), fuzzy, and fuzzy AHP methods with actual rice yield in the study area it has been showed that the results of the latter method are more consistent with the natural conditions governing the studied area. The fuzzy-logic based methods can consider continuous land variations and consequently have a higher ability to provide soil spatial variability. In contrast, Boolean logic-based methods lose a considerable amount of data through the land evaluation processes. Also, through using the fuzzy AHP method, the use of different weights and membership functions can lead to different results. Therefore, in applying the theory of fuzzy sets to assess land suitability, selection of weights and membership functions have a high importance.

Several studies (Braimoh et al. 2004, Elaalem 2010, Keshavarzi et al. 2010, Moreno 2007) indicated that the relative impact of evaluation criteria on crop production (adequate weight selection) and the appropiate selection of membership functions to achieve realistic results in land suitability evaluation are needed. Therefore, the use of the fuzzy AHP method in assessing the land suitability of the studied area for rice growing can be a suitable alternative to the traditional method. In line with the aforementioned findings, the results of the current study emphasizes that the fuzzy AHP method might be a relevant alternative to the conventional and traditional land suitability evaluation. 


\section{CONCLUSIONS}

The proposed approach based on the fuzzy AHP method has great potential to model land use suitability evaluation problem. The results showed that the compatibility percentage between the representative pedon $(0-100 \mathrm{~cm})$ and observation points was remarkable for 0-50 and 0-75 cm depths in fuzzy and fuzzy AHP methods. According to cost and time-consuming land suitability studies, the land suitability evaluation by using $0-50 \mathrm{~cm}$ results might be a relevant alternative to the optimal soil depth for land suitability evaluation in paddy fields in the study area. With respect to the findings of the current research, however, considerable attention should be given to evaluation of our findings at the national level in order to achieve greater accuracy.

\section{REFERENCES}

[1] Akef, M., 2005. Semi-Detailed Soil Classification of the Unit of G4 of Sepidrood's Irrigation and Drainage Network (in Persian). Local Water Company of Guilan Province, Iran.

[2] Ayoubi, S., Zamani, S.M., Khormali, F., 2009. Wheat Yield Prediction Through Soil Properties Using Principal Component Analysis (in Persian). Iranian Journal of Soil and Water Research, 40(1): 51-57.

[3] Bacic, I., 2003. Demand-Driven Land Evaluation with Case Studies in Santa Catarina. ITC dissertation, Brazil, p. 105.

[4] Bagherzadeh, A., Gholizadeh, A., 2016. Qualitative Land Suitability Evaluation by Parametric and Fuzzy Approaches for Sugar Beet Crop in Sabzevar Plain, the Northeast of Iran. Agricultural Research, 5(3): 277-284.

[5] Banai, R., 1993. Fuzziness in Geographical Information Systems: Contributions from the Analytic Hierarchy Process. International Journal of Geographical Information Science, 7(4): 315-329.

[6] Bouma, J., Finke, P., 1993. Origin and Nature of Soil Resource Variability. Soil Specific Crop Management, Madison, Wisconsin, ASA-CSSA-SSSA, pp. 3-14.

[7] Braimoh, A.K., Vlek, P.L., Stein, A., 2004. Land Evaluation for Maize Based on Fuzzy Set and Interpolation. Journal of Environmental Management, 33(2): 226-238.

[8] Ceballos-Silva, A., Lopez-Blanco, J., 2003. Delineation of Suitable Areas for Crops Using a Multi-Criteria Evaluation Approach and Land Use/Cover Mapping: A Case Study in Central Mexico. Agricultural Systems, 77(2): 117-136.

[9] Cheng, Y.-Q., Yang, L.-Z., Cao, Z.-H., Ci, E., Yin, S., 2009. Chronosequential Changes of Selected Pedogenic Properties in Paddy Soils as Compared with Non-Paddy Soils. Geoderma, 151(1-2): 31-41.

[10] Davatgar, N., Neishabouri, M., Sepaskhah, A., 2012. Delineation of Site Specific Nutrient Management Zones for a Paddy Cultivated Area Based on Soil Fertility Using Fuzzy Clustering. Geoderma, 173: 111-118.

[11] De la Rosa, D., van Diepen, C., 2002. Qualitative and Quantitative Land Evaluation, in 1.5. Land Use and Land Cover. Encyclopedia of Life Support System, Eolss Publishers, Oxford, UK.

[12] Elaalem, M., 2010. The Application of Land Evaluation Techniques in Jeffara Plain in Libya Using Fuzzy Methods. University of Leicester.

[13] Fu, W., Tunney, H., Zhang, C., 2010. Spatial Variation of Soil Nutrients in a Dairy Farm 
and Its Implications for Site-Specific Fertilizer Application. Soil Tillage Research, 106(2): 185-193.

[14] Gajri, P.R., Arora, V.K., Prihar, S.S., 2002. Tillage for Sustainable Cropping. Food Products Press, New York, p. 196

[15] GAOGP, 2007. Land Suitability for Second Crops in Guilan Paddy Fields (in Persian). Jahad Agriculture of Guilan Province, Rasht, Iran.

[16] Givi, J., 1997. Qualitative Evaluation of Land Suitability for Field and Fruit Crops. Iranian Soil and Water Research Institute, Tehran, Iran, pp. 1-115.

[17] Jaiyeoba, I., 2003. Changes in Soil Properties Due to Continuous Cultivation in Nigerian Semiarid Savannah. Soil Tillage Research, 70(1): 91-98.

[18] JAOGP, 2017. Agriculture Production Stattistics of Guilan Province. Jahad Agriculture of Guilan Province.

[19] Jian-Bing, W., Du-Ning, X., Xing-Yi, Z., Xiu-Zhen, L., Xiao-Yu, L., 2006. Spatial Variability of Soil Organic Carbon in Relation to Environmental Factors of a Typical Small Watershed in the Black Soil Region, Northeast China. Environmental Monitoring and Assessment, 121(1): 597-613.

[20] Kassam, A.H., 1977. Net Biomass and Yields of Crops. Consultant's Report. Agro-ecological zones project. AGL-FAO, Rome.

[21] Keshavarzi, A., Sarmadian, F., Heidari, A., Omid, M., 2010. Land Suitability Evaluation Using Fuzzy Continuous Classification (a Case Study: Ziaran Region). Modern Applied Science, 4(7): 72 .

[22] Kögel-Knabner, I., Amelung, W., Cao, Z., Fiedler, S., Frenzel, P., Jahn, R., Kalbitz, K., Kölbl, A., Schloter, M., 2010. Biogeochemistry of Paddy Soils. Geoderma, 157(1-2): 1-14.

[23] Kurtener, D., Krueger-Shvetsova, E., Dubitskaia, I., 2004. Quality Estimation of Data Collection. UDMS, UDMS Press, Venice, pp. 9101-9109.

[24] Lal, R., 2004. Offsetting China's $\mathrm{CO}_{2}$ Emissions by Soil Carbon Sequestration. Climate Change, 65(3): 263-275.

[25] Liu, Z., Zhou, W., Shen, J., He, P., Lei, Q., Liang, G., 2014. A Simple Assessment on Spatial Variability of Rice Yield and Selected Soil Chemical Properties of Paddy Fields in South China. Geoderma, 235: 39-47.

[26] Mahdavi Firoozabadi, M., Esfandiarpour Borujeni, I., Bagheri Bodaghabadi, M., Kamali, A., 2016. Comparison of Two Fuzzy Methods to Determine the Optimum Soil Depth in Land Suitability Evaluation for Wheat (in Persian). Journal of Soil Management and Sustainable Production, 6(3): 101-116.

[27] Mahmoud Soltani, S., Hanafi, M.M., Samsuri, A.W., Muhammed, S.K.S., Hakim, M.A., 2016. Rice Growth Improvement and Grains Bio-Fortification Through Lime and Zinc Application in Zinc Deficit Tropical Acid Sulphate Soils. Chemical Speciation \& Bioavailability, 28(1-4): 152-162.

[28] Mahmoud Soltani, S., Hanafi, M.M., Wahid, S.A., Kharidah, S.M.S., 2015. Zinc Fractionation of Tropical Paddy Soils and Their Relationships with Selected Soil Properties. Chemical Speciation \& Bioavailability, 27(2): 53-61.

[29] Malczewski, J., 1996. A GIS-Based Approach to Multiple Criteria Group Decision-Making. International Journal of Geographical Information Science, 10(8): 955-971.

[30] McBratney, A.B., Odeh, I.O., 1997. Application of Fuzzy Sets in Soil Science: Fuzzy Logic, Fuzzy Measurements and Fuzzy Decisions. Geoderma, 77(2-4): 85-113.

[31] Moreno, J.F.S., 2007. Applicability of Knowledge-Based and Fuzzy Theory-Oriented Approaches to Land Suitability for Upland Rice and Rubber, as Compared to the Farmers' Perception: A Case Study of Lao PDR. ITC, p. 33.

[32] Owliaie, H.R., Ghiri, M.N., 2013. Effect of Long-Term Rice Cultivation on Physico-Chemical Properties and Clay Mineralogy of Soils in Yasouj Region. Journal of Agricultural Science and Technology, 17(65): 39-50. 
[33] Pan, G., Wu, L., Li L., Zhang, X., Gong, W., Wood, Y., 2008. Organic Carbon Stratification and Size Distribution of Three Typical Paddy Soils from Taihu Lake Region, China. Journal of Environmental Sciences, 20(4): 456-463.

[34] Prakash, J., 2003. Land Suitability Evaluation for Agricultural Crops: A Fuzzy Multicriteria Decision-Making Approach. Enscheda, the Netherlands.

[35] Qiu, F., Chastain, B., Zhou, Y., Zhang, C., Sridharan, H., 2014. Modeling Land Suitability/ Capability Using Fuzzy Evaluation. GeoJournal, 79(2): 167-182.

[36] Rossiter, D.G., 1996. A Theoretical Framework for Land Evaluation. Geoderma, 72(3-4): 165-190.

[37] Ruan, D., 1990. A Critical Study of Widely Used Fuzzy Implication Operators and Their Influence on the Inference Rules in Fuzzy Expert Systems. Ghent University.

[38] Saaty, T.L., 2014. Analytic Hierarchy Process. Wiley StatsRef: Statistics Reference Online.

[39] Sarma, V.A.K., 2006. Mapping of the Soil. Science publishers, NH, USA.

[40] Servati, M., Jafarzadeh, A., Ghorbani, M., Shahbazi, F., Davatgar, N., 2014. Land Suitability Evaluation for Alfalfa in Khajeh Region Using the Parametric Square Root Method and Fuzzy Set Theory (in Persian). Water and Soil Science, 24(2): b93-105.

[41] SSS (Soil Survey Staff), 2017. Web Soil Survey.

[42] Sys, C., Van Ranst, E., Debaveye, J., 1991. Land Evaluation. Part II: Methods in Land Evaluation. Agricultural Publications, 7: 247, Brussels.

[43] Sys, C., Van Ranst, E., Debaveye, J., 1993. Land Evaluation. Part III: Crop Requirements. Agricultural Publications, 7, Brussels.

[44] Tang, H., Van Ranstb, E., Groenemansh, R., 1997. Application of Fuzzy Set Theory to Land Suitability Assessment. Soil Science, 2: 191-203.

[45] USDA, 2014. Keys to Soil Taxonomy. Soil Survey Staff.

[46] Van Niekerk, J., Von Solms, R., 2010. Information Security Culture: A Management Perspective. Computers \& Security, 29(4): 476-486.

[47] Van Ranst, E., Tang, H., Groenemam, R., Sinthurahat, S., 1996. Application of Fuzzy Logic to Land Suitability for Rubber Production in Peninsular Thailand. Geoderma, 70(1): 1-19.

[48] Wang, Z.M., Song, K.S., Zhang, B., Liu, D.W., Li, X.Y., Ren, C.Y., Zhang, S.M., Luo, L., Zhang, C.H., 2009. Spatial Variability and Affecting Factors of Soil Nutrients in Croplands of Northeast China: A Case Study in Dehui County. Plant, Soil and Environment, 55(3): $110-120$.

[49] Yaghmaeian Mahabadi, N., Givi, J., Naderi Khorasgani, M., Mohammadi, J., Poch Claret, R., 2012. Land Suitability Evaluation for Alfalfa and Barley Based on Fao and Fuzzy Multi-Criteria Approaches in Iranian Arid Region. Desert, 17(1): 77-89.

[50] Yaghmaeian Mahabadi, N., Rahimi Mashkale, M., 2016. Comparison of Parametric and Fuzzy Analytic Hierarchy Process in Land Evaluation (Case Study: Varamin Region). Urban Management, 45: 239-248.

[51] Zhang, X.-Y., Yue-Yu, S., Zhang, X.-D., Kai, M., Herbert, S., 2007. Spatial Variability of Nutrient Properties in Black Soil of Northeast China. Pedosphere, 17(1): 19-29.

[52] Zhu, A.-X., Yang, L., Li, B., Qin, C., Pei, T., Liu, B., 2010. Construction of Membership Functions for Predictive Soil Mapping under Fuzzy Logic. Geoderma, 155(3-4): 164-174. 